\title{
Sistem Pendukung Keputusan Seleksi Mahasiswa Penerima Beasiswa menggunakan Metode Fuzzy Multiple Attribute Decision Making (FMADM) dan Simple Additive Weighting (SAW)
}

\section{Laurentinus}

Teknik Informatika STMIK Atma Luhur Pangkalpinang, Indonesia

\section{KEYWORDS}

Five words maximum, comma separated

\section{CORRESPONDENCE}

Phone: +62 (0751) 12345678

E-mail: first_author@affiliation.xx.xx

\section{INTRODUCTION}

STMIK Atma Luhur adalah perguruan tinggi yang menyediakan beasiswa bagi para mahasiswa maupun mahasiswi yang berprestasi di bidang akademik maupun non akademik, terdapat beasiswa kurang mampu ataupun bagi yang berprestasi. Masalah yang dihadapi pada STMIK Atma Luhur belum terdapatnya sebuah sistem pendukung keputusan, agar lebih efektif dalam pemilihan beasiswa untuk mahasiswa ataupun mahasiswi.

Pada penelitian ini akan di rancang sebuah sistem pendukung keputusan dengan metode FMADM dalam pembobotan dan Simple Additive Weighting (SAW) berbasis android. Metode ini dipilih agar lebih mudah dan lebih akurat dalam perankingan dari setiap kriteria yang telah ditentukan dan kemudian akan dilakukan proses perangkingan untuk menentukan alterntif terbaik. Dalam penelitian ini terdapat 3 variabel, berupa beasiswa berprestasi, beasiswa kurang mampu dan beasiswa bagi yang mampu. Sistem pendukung keputusan penerimaan beasiswa. Penlitian ini berbasis android di pilih karena mempermudah serta mempercepat proses penginputan data beasiswa. Pada sistem ini penulis akan membuat sebuah sistem yang berguna bagi sebuah perguruan tinggi agar dapat membantu pekerjaan menjadi lebih mudah untuk di selesaikan.
Beasiswa ditentukan oleh bagian Kemahasiswaan. Namun sayangnya variabel yang dinilai terlalu sedikit hingga faktor ketidak jelasan penilaian.

\section{METHOD}

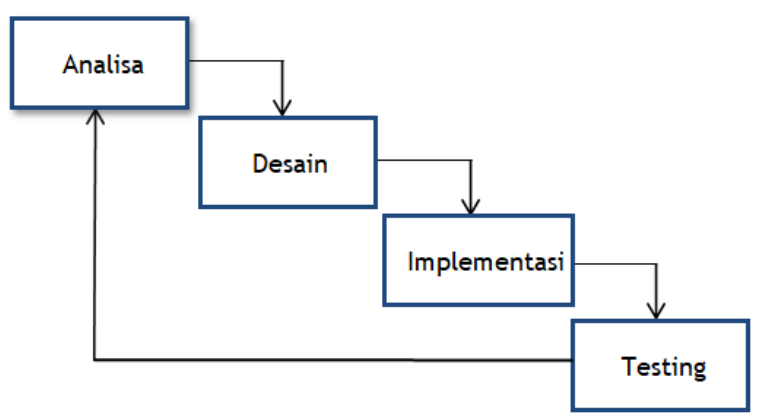

Gambar 1. Model Waterfall

Dalam hal ini peneliti menggunakan metode waterfall untuk melakukan pengembangan sistem. Tahapan dari model waterfall yang diterapkan sebagai berikut:

1. Analisa

Sebelum memulai penelitian ini sangat diperlukan analisa sistem yaitu komunikasi dengan bagian kemahasiswaan 
menggunakan teknik wawancara, observasi ataupun studi pustaka mengenai kriteria beasiswa.

2. Desain

Tahap ini merupakan tahapan perencanaan analisis kebutuhan fungsional maupun nonfungsional yang diperlukan dalam pembuatan sistem dan aplikasi serta merupakan proses mendesain rancangan layar dan mendesain metode FMADM dan metode SAW (Simple Additive Weighting) didalam sistem dan aplikasi. Tahapan ini juga merupakan tahapan coding.

3. Implementasi

Pada tahapan ini, SPK (Sistem Pendukung Keputusan) penentuan beasiswa berbasis android akan diuji atau ditest untuk melihat apakah masih ada kesalahan atau tidak.

4. Testing

Pada tahapan ini, penulis akan melakukan pengujian menggunakan pengujian Blackbox.

Metode SAW merupakan metode yang paling mudah untuk diaplikasikan, karena mempunyai algoritma yang tidak rumit. Metode SAW [7] sering juga dikenal istilah metode penjumlahan terbobot. Konsep dasar metode SAW adalah mencari penjumlahan terbobot dari rating kinerja pada setiap alternatif pada semua atribut.

Langkah-langkah metode dalam metode SAW adalah :

1. Memberikan nilai bobot preferensi (W) oleh pengambil keputusan untuk masing- masing kriteria yang sudah ditentukan.

$$
W=\left[\begin{array}{llllll}
W_{l} & W_{2} & W_{3} & \ldots & W_{j}
\end{array}\right](1) .
$$

2. Melakukan normalisasi matriks keputusan $\mathrm{Z}$ dengan cara menghitung nilai rating kinerja ternormalisasi $\left(r_{i j}\right)$ dari alternatif $\mathrm{A}_{\mathrm{i}}$ pada $\mathrm{C}_{\mathrm{j}}$

$$
r_{i j}\left\{\begin{array}{l}
\frac{x_{i j}}{M A X_{i}\left(x_{i j}\right)} \\
\frac{\operatorname{MIN}_{i}\left(x_{i j}\right)}{x_{i j}}
\end{array}\right.
$$

Dikatakan atribut keuntungan apabila atribut banyak memberikan keuntungan bagi pengambil keputusan, sedangkan atribut biaya merupakan atribut yang banyak memberikan pengeluaran jika nilainya semakin besar bagi pengambil keputusan.

3. Hasil dari nilai rating kinerja ternormalisasi $\left(\mathrm{r}_{\mathrm{ij}}\right)$ membentuk matriks ternormalisasi ( $\mathrm{R})$

$$
R=\left[\begin{array}{ccc}
r_{11} r_{12} & \cdots & r_{i j} \\
\vdots & \ddots & \vdots \\
r_{i 1} & r_{12} \cdots & r_{i j}
\end{array}\right]
$$

4. Melakukan proses perankingan dengan cara mengalikan matriks ternormalisasi $(\mathrm{N})$ dengan nilai bobot preferensi (W).

5. Menentukan nilai preferensi untuk setiap alternatif $\left(\mathrm{V}_{\mathrm{i}}\right)$ dengan cara menjumlahkan hasil kali antara matriks ternormalisasi $(\mathrm{N})$ dengan nilai bobot preferensi (W).

$$
\mathrm{V}_{\mathrm{i}}=\sum_{j=1}^{n} \mathrm{w}_{\mathrm{j}} \mathrm{r}_{\mathrm{ij}}
$$

Nilai $V_{i}$ yang lebih besar mengindikasikan bahwa alternatif $A_{i}$ lebih terpilih.

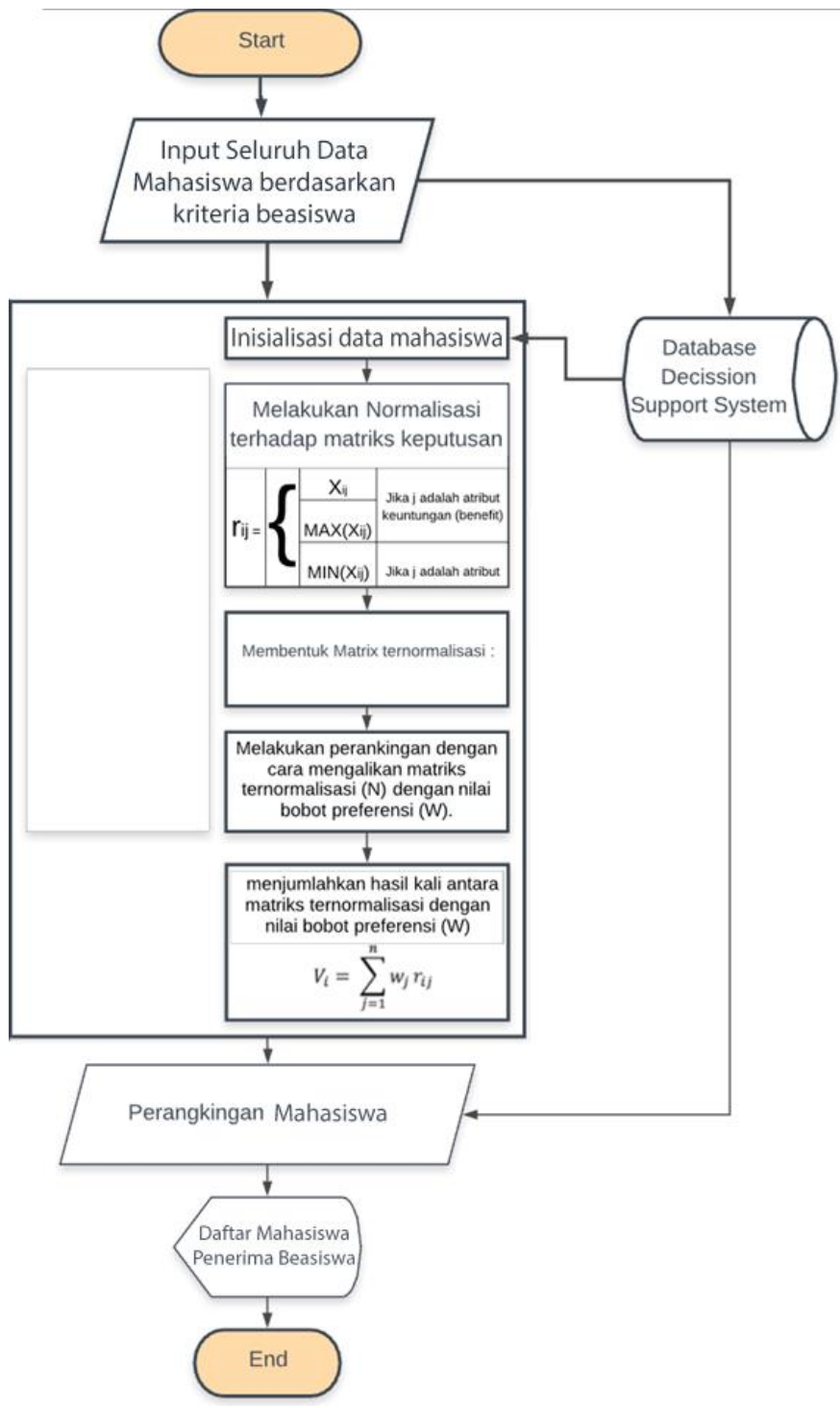

Gambar 2 Diagram Alur Pengambil Keputusan menggunakan metode SAW

\section{RESULTS AND DISCUSSION}

Berdasarkan dari hasil wawancara terdapat sub kriteria yang akan di buat menjadi sebuah interval, berikut interval yang terdapat pada beberapa sub kriteria dari kriteria yang di ambil

1. Interval Memiliki KTM (11)

Range interval Memiliki KTM (K11) terbagi atas 2 bilangan fuzzy yaitu :

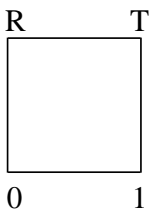

2. Interval Surat Keterangan Tidak Mampu (12)

Range interval Memiliki KTM (K12) terbagi atas 2 bilangan fuzzy yaitu :

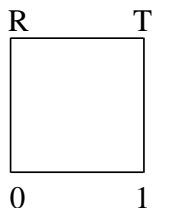


3. Interval Surat Penghasilan Orang Tua (13)

Range interval Memiliki KTM (K13) terbagi atas 2 bilangan fuzzy yaitu :

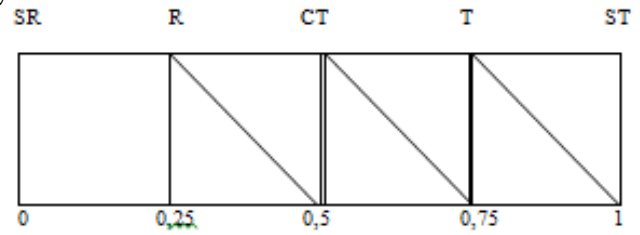

4. Interval Nilai Raport/ Transkip Nilai (K14)

Range interval Memiliki KTM (K14) terbagi atas 2 bilangan fuzzy yaitu :

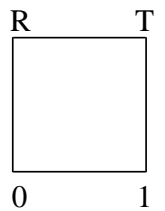

5. Interval Jumlah Tanggungan Orang Tua (15)

Range interval Memiliki KTM (K15) terbagi atas 2 bilangan fuzzy yaitu :

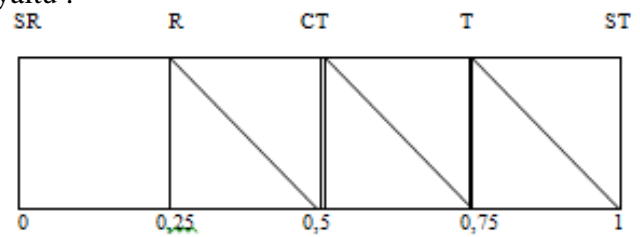

6. Interval Sertifikat (K16)

Range interval Memiliki KTM (K16) terbagi atas 2 bilangan fuzzy yaitu :

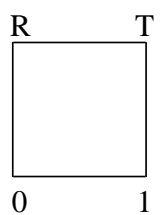

Adapun hasil dari keluaran (output) dari metode FMADM dari penelitian ini adalah pembobotan kriteria Beasiswa Kurang Mampu dan Beasiswa Prestasi. Pembobotan ini akan menjadi nilai ukur yang digunakan oleh metode SAW di proses perankingan siswa penerima beasiswa.

\section{Beasiswa Kurang Mampu (C1)}

Tabel 1 Kriteria Beasiswa Kurang Mampu

Tabel 1 Kriteria Beasiswa Kurang Mampu
\begin{tabular}{|c|c|c|c|c|}
\hline \multicolumn{2}{|c|}{ Sub Kriteria } & Keterangan & $\begin{array}{c}\text { Detail } \\
\text { Nilai }\end{array}$ & Nilai \\
\hline K11 & Memiliki KTM & Ya/Tidak & 0,15 & $1 / 0$ \\
\hline K12 & Surat Keterangan & Ya/Tidak & 0,17 & $1 / 0$ \\
& Tidak Mampu & & & \\
\hline K13 & Penghasilan & Rp. $500.000-$ & 0,18 & 5 \\
& Orang Tua & 1.000 .000 & 0,12 & 3 \\
& & Rp. $1.000 .000-$ & 0,06 & 1 \\
& & 1.500 .000 & & \\
& & Rp. $1.500 .000-$ & & \\
\hline K14 & Nilai Raport/ & Ya/Tidak & 0,2 & $1 / 0$ \\
& Transkip Nilai & & & \\
\hline K15 & Jumlah & 1 Anak & 0,16 & 5 \\
& Tanggungan & 2 Anak & 0,128 & 4 \\
& Orang Tua & 3 Anak & 0,096 & 3 \\
& & 4 Anak & 0,064 & 2 \\
& & 5 Anak & 0,32 & 1 \\
\hline K16 & Sertifikat & Ya/Tidak & 0,14 & $1 / 0$ \\
\hline
\end{tabular}

\section{Kriteria Beasiswa Prestasi (C3)}

Tabel 2 Kriteria Beasiswa Prestasi

\begin{tabular}{|c|c|c|c|c|}
\hline \multicolumn{2}{|c|}{ Sub Kriteria } & Keterangan & $\begin{array}{c}\text { Detail } \\
\text { Nilai }\end{array}$ & Nilai \\
\hline K21 & Mahasiswa Aktif & Ya/Tidak & 0,14 & $1 / 0$ \\
\hline K22 & Memiliki KTM & Ya/Tidak & 0,15 & $1 / 0$ \\
\hline K23 & $\begin{array}{c}\text { Transkip Nilai } \\
\text { diatas rata-rata }\end{array}$ & Ya/Tidak & 0,2 & $1 / 0$ \\
\hline K24 & IPK Minimal 3,0 & Ya/Tidak & 0,18 & $1 / 0$ \\
\hline K25 & Piagam Prestasi & Ya/Tidak & 0,17 & $1 / 0$ \\
\hline K26 & $\begin{array}{c}\text { Tidak Menerima } \\
\text { Beasiswa Dari } \\
\text { Sumber Lain }\end{array}$ & Ya/Tidak & 0,16 & $1 / 0$ \\
\hline
\end{tabular}

\section{Tahapan Perhitungan Metode SAW} SAW :

Berikut adalah proses dari perhitungan Algoritma metode

Tahapan pertama dalam metode ini harus mengumpulkan rating untuk kecocokan nilai keseluruhan. Berikut rating yang di kumpulkan nilai untuk kriteria beasiswa kurang mampu :

Tabel 3 Rating Kecocokan Nilai

\begin{tabular}{|c|c|c|c|c|c|c|}
\hline \multirow{2}{*}{ Mahasiswa } & \multicolumn{5}{|c|}{ Kriteria Beasiswa Kurang Mampu } \\
\cline { 2 - 7 } & K11 & K12 & K13 & K14 & K15 & K16 \\
\hline Mahasiswa 1 & 1 & 1 & 3 & 1 & 2 & 1 \\
\hline Mahasiswa 2 & 1 & 1 & 1 & 1 & 4 & 1 \\
\hline
\end{tabular}

Setiap nilai yang di hasilkan dari setiap sub kriteria merupkan nilai kecocokan (berdasarkan kriteria beasiswa kurang mampu), maka di tentukanlah nilai bobot maksimal dari kriteria beasiswa kurang mamp. Nilai bobot maksimal di dapatkan dari wawancara dari bagian kemahasiswaan STMIK Atma Luhur Pangkalpinang. Berikut tabel dari bobot maksimal dari kriteria beasiswa kurang mampu :

Tabel 4 Bobot Maksimal

\begin{tabular}{|c|c|c|c|c|c|c|}
\hline & K11 & K12 & K13 & K14 & K15 & K16 \\
\hline \multirow{2}{*}{$\mathrm{W}$} & 0,15 & 0,17 & 0,12 & 0,2 & 0,064 & 0,14 \\
\cline { 2 - 7 } & 0,15 & 0,17 & 0,06 & 0,2 & 0,128 & 1 \\
\hline
\end{tabular}

Tahap selanjutnya buat matriks keputusan X, Matriks ini diambil dari tabel 3.x, rating nilai kecocokan nilai sebagai berikut :

$$
X=\left\{\begin{array}{llllll}
1 & 1 & 3 & 1 & 2 & 1 \\
1 & 1 & 1 & 1 & 4 & 1
\end{array}\right\}
$$

Tahap selanjutnya melakukan normalisasi matriks $X$ untuk mengjhitung nilai dari masing-masing, berdasrkan kriteria yang di pilih. Berikut ini perhitungan normalisasi untuk mencari nilai $\mathrm{r} 11, \mathrm{r} 12, \mathrm{r} 13, \mathrm{r} 14, \mathrm{r} 15, \mathrm{r} 16$ untuk mahasiswa 1 dan mahasiswa 2

$$
\begin{aligned}
& \mathrm{R} 11=\frac{1}{\operatorname{Max}(1)}=\frac{1}{1}=1 \\
& \mathrm{R} 12=\frac{1}{\operatorname{Max}(1)}=\frac{1}{1}=1 \\
& \mathrm{R} 13=\frac{1}{\operatorname{Max}(3)} \quad=\frac{3}{3}=1 \\
& \mathrm{R} 14=\frac{1}{\operatorname{Max}(1)}=\frac{1}{1}=1 \\
& \mathrm{R} 15=\frac{1}{\operatorname{Max}(2)}=\frac{2}{5}=0,4 \\
& \mathrm{R} 16=\frac{1}{\operatorname{Max}(1)}=\frac{1}{1}=1 \\
& \mathrm{R} 11=\frac{1}{\operatorname{Max}(1)}=\frac{1}{1}=1 \\
& \mathrm{R} 12=\frac{1}{\operatorname{Max}(1)}=\frac{1}{1}=1 \\
& \mathrm{R} 13=\frac{1}{\operatorname{Max}(3)}=\frac{1}{3}= \\
& \mathrm{R} 14=\frac{1}{\operatorname{Max}(1)}=\frac{1}{1}=1
\end{aligned}
$$




$$
\begin{aligned}
& \mathrm{R} 15=\frac{1}{\operatorname{Max}(5)}=\frac{4}{5}=0,8 \\
& \mathrm{R} 16=\frac{1}{\operatorname{Max}(1)}=\frac{1}{1}=1
\end{aligned}
$$

Hasil dari perhitungan normalisasi $\left(r_{i j}\right)$ membentuk matriks ternormalisasi (R).

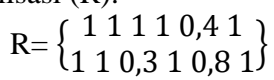

Kemudian melakukan proses perangkingan dengan cara mengalikan matriks normalisasi $(\mathrm{R})$ dengan nilai bobot prefrensi (W) dan menentukan nilai preferensi untuk setiap alternatif (Vi) dengan cara menjumlahkan hasil kali antara matriks normalisasi (3) dengan nilai bobot preferensi (W). Untuk nilai bobot preferensi bobot $(\mathrm{W})$ oleh pengamil keputusan untuk masingmasing kriteria yang telah di tentukan :

$$
\begin{aligned}
& \mathrm{W}=\left[\begin{array}{llllll}
0,15 & 0,17 & 0,12 & 0,2 & 0,064 & 0,14
\end{array}\right] \\
& \mathrm{W}=\left[\begin{array}{llllll}
0,15 & 0,17 & 0,06 & 0,2 & 0,128 & 0,14
\end{array}\right]
\end{aligned}
$$

Sehingga di dapat nilai :

$$
\begin{aligned}
& \mathrm{V} 1=(0,15) *(1)+(0,17) * 1+(0,12) * 1+(0,2) * 1+ \\
& (0,064) * 0,4+(0,14) * 1=0,8056 \\
& \mathrm{~V} 2=(0,15) *(1)+(0,17) * 1+(0,06) * 0,3+(0,2) * 1+ \\
& (0,128) * 0,8+(0,14) * 1=0,7804
\end{aligned}
$$

Kesimpulan dari data di atas adalah bahwa nilai yang tertinggi ada pada V1, dengan demikian alternaif yang terbaik dapat di ambil dari alternatif mahasiswa V1 untuk beasiswa kurang mampu di STMIK Atma Luhur Pangkalpinang.

\section{IMPLEMENTASI}

Berikut adalah hasil dari tampilan sistem pendukung keputusan untuk seleksi penerimaan beasiswa :

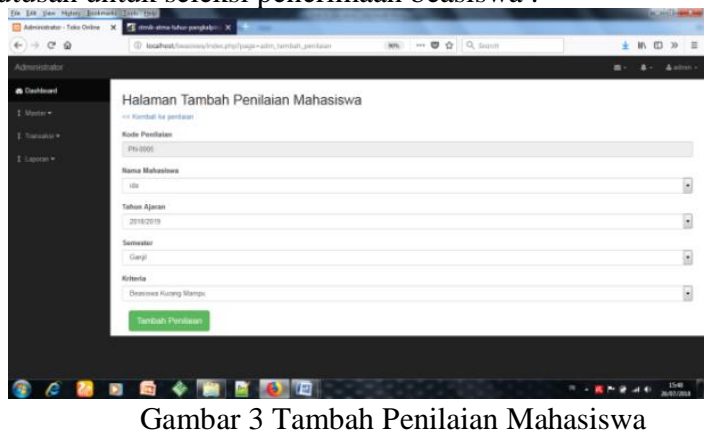

Pada halaman tambah mahasiswa admin dapat menginput data-data mahasiswa yang telah menyerahkan berkas ke bagian kemahasiswaan kemudian admin akan menginput data-data mahasiswa.

Pada tampilan ini, admin dapat memilih nama mahasiswa, tahun ajaran, semester dan kriteria untuk melakukan penilaian.

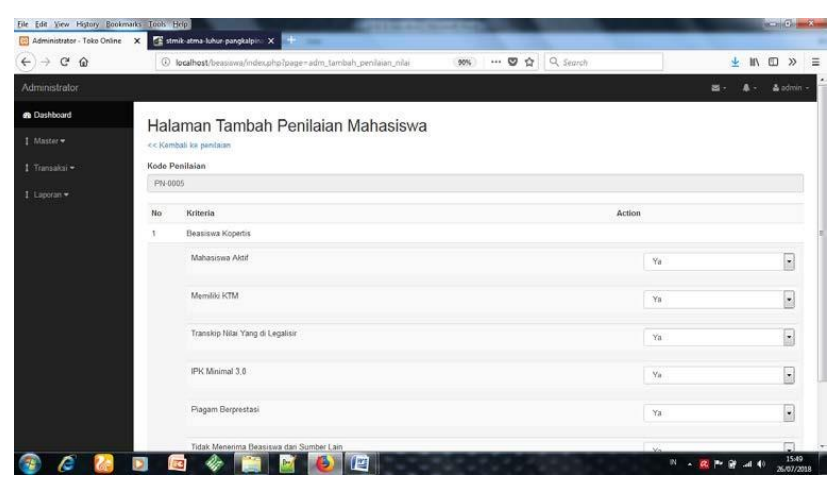

Gambar 4 Tampilan Penilaian Sub Kriteria Mahasiswa

Setelah Seluruh Mahasiswa dinilai maka proses selanjutnya yaitu menghitung menggunakan metode SAW sehingga dapat ranking mahasiswa yang layak mendapatkan beasiswa berdasarkan tahun ajaran dan semester.

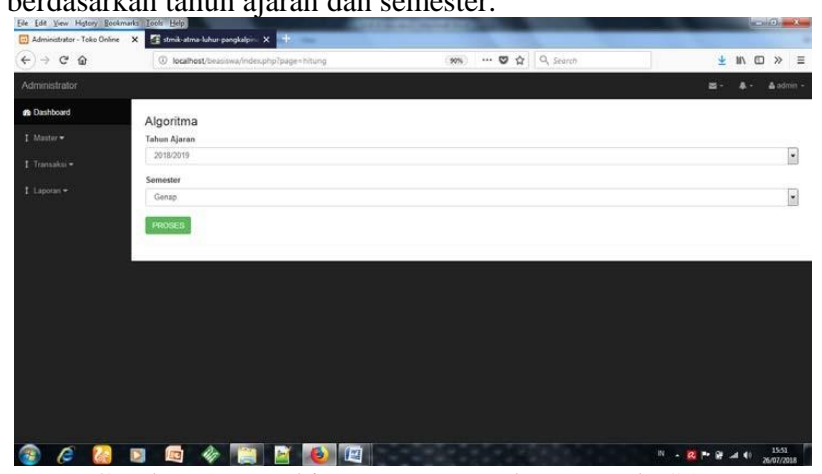

Gambar 5 Menghitung menggunakan metode SAW

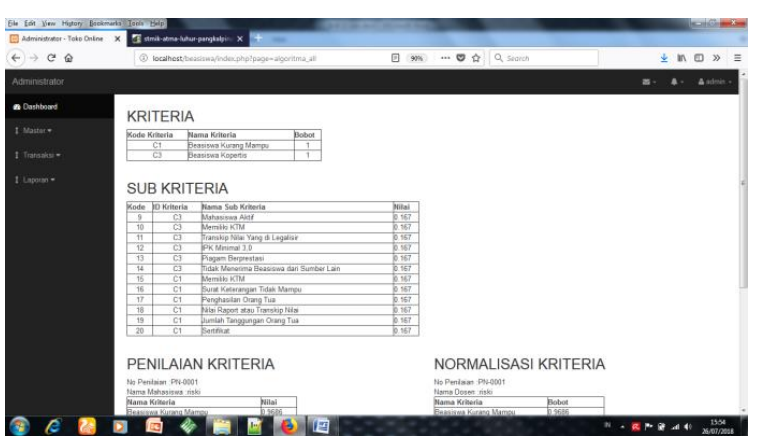

Gambar 6 Tampilan Perangkingan menggunakan Metode SAW

Pada halaman tampilan perankingan menggunakan metode SAW akan tampil hasil dari proses perhitungan algoritma dan akan muncul nilai-nilai mahasiswa yang telah mengikuti seleksi penerimaan beasiswa.

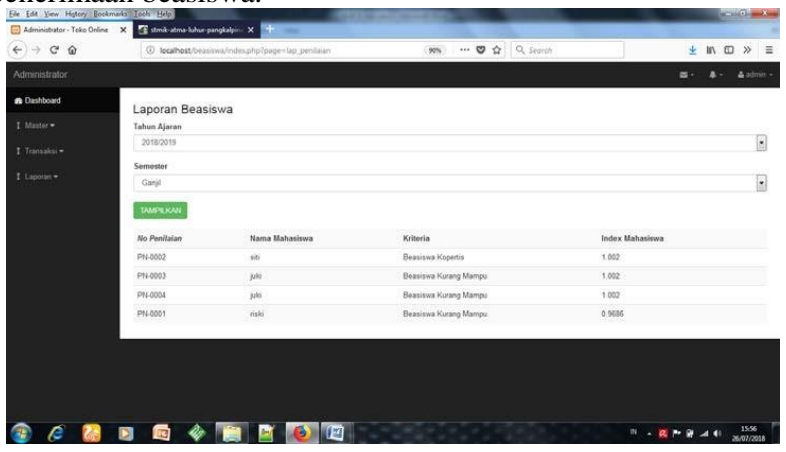

Gambar 7 Laporan Data Mahasiswa Penerima Beasiswa

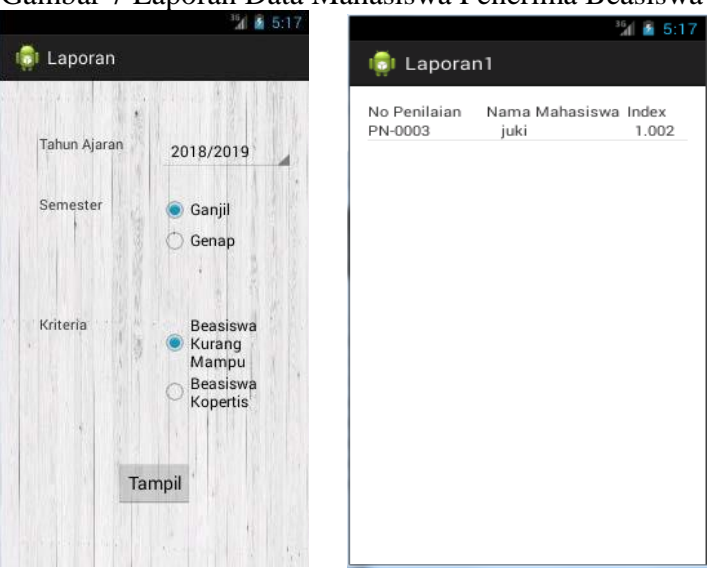

Gambar 8 Tampilan Laporan Android

Pada halaman tampilan laporan android sistem hanya menampilkan data-data rangking mahasiswa yang mendapatkan beasiswa, yang bisa di akses oleh mahasiswa.

Pengujian dilakukan menggunakan metode blackbox dengan persentase $98 \%$ keseluruhan system berjalan dengan baik. 


\section{CONCLUSIONS}

Setelah mempelajari permasalahan yang dihadapi dan juga solusi pemecahan yang diusulkan, maka dapat di tarik kesimpulan sebagai berikut:

1. Simple Additive Weighting (SAW) merupakan perhitungan nilai secara terbobot dan perhitungan yang akurat, dakam menganalisa cara perhitungan nilai bobot dari kriteria agar dapat membantu pihak STMIK Atma Luhur dalam menentukan beasiswa kepada mahasiswa yang memenuhi kriteria.

2. Kelebihan dari sistem ini dapat membantu dan mempermudah pihak kampus terutama bagian kemahasiswaan untuk lebih mudah dalam penyeleksian mahasiswa yang wajib mendapatkan beasiswa, kekurangan dari sistem ini masih perlu pemeliharaan lebih lanjut agar dapat mempermudah pihak kampus dan bagian kemahasiswaan.

\section{REFERENCES}

[1] Surya, Candra. (2015). Sistem Pendukung Keputusan Rekomendasi Penerima Beasiswa Menggunakan Fuzzy Multi Attribut Decision Making (FMADM) dan Simple Additive Weighting (SAW). Jurnal Rekayasa Elektrika. 11. 149. 10.17529/jre.v11i4.2364.

[2] Arizza Candra, Galih \& Rawansyah, Rawansyah \& Setyo Astuti, Elly. (2017). Sistem Pendukung Keputusan Pemilihan Mahasiswa Berprestasi Dengan Metode Fuzzy Multi-Attribute Decision Making Saw. Jurnal Informatika Polinema. 1. 18. 10.33795/jip.v1i3.108.

[3] Yani, Fitri \& Yuranda, Yuranda \& Pajarini, Peti \& Rosmawati, Rosmawati. (2018). Penentuan Beasiswa Pada SMPN 6 Pangkalpinang Menggunakan Metode SAW dan Fuzzy Multi Attribute Decision Making. Jurnal RESTI (Rekayasa Sistem dan Teknologi Informasi). 2. 437-443. 10.29207/resti.v2i1.325.

[4] Mukhtar, Mukhtar \& Munawir, Munawir. (2018). Aplikasi Decision Support System (DSS) dengan Metode Fuzzy Multiple Attribute Decission Making (FMADM) Studi Kasus : AMIK Indonesia Dan STMIK Indonesia. Jurnal JTIK (Jurnal Teknologi Informasi dan Komunikasi). 2. 57. 10.35870/jtik.v2i1.54.

[5] Safii, M. (2017). Sistem Pendukung Keputusan Penerima Beasiswa PPA Dan BBM Menggunakan Metode Simple Additive Weighting (SAW). Jurasik (Jurnal Riset Sistem Informasi dan Teknik Informatika). 2. 75. 10.30645/jurasik.v2i1.21.

[6] Aditya Agassi V, Yoga \& Dharma W, Indra \& Romlah, Romlah. (2014). SISTEM PENDUKUNG KEPUTUSAN PENERIMAAN BEASISWA DENGAN METODE SIMPLE ADDITIVE WEIGHTING (SAW) DI POLITEKNIK NEGERI MALANG. Jurnal Informatika Polinema. 1. 53. 10.33795/jip.v1i1.91.

[7] Kusumadewi., Sri, Hartati., Sri, Harjoko., Agus, dan Wardoyo., Retantyo, 2006. Fuzzy Multi Attributte Decision Making (Fuzzy MADM). Graha Ilmu, Yogyakarta.

[8] Deni, Widayanti, Sudana, Oka, dan Sasmita, Arya, 2013, Analysis and Implementation Fuzzy Multi-Attribute Decision Making SAW Method for Selection of High Achieving Students in Faculty Level. IJCSI International Journal of Computer Science Issues, No 2, Vol. 10, Issue 1. 